\title{
Bioactive surfaces from seaweed-derived alginates for the cultivation of human stem cells
}

\author{
Michael M. Gepp ${ }^{1} \cdot$ Benjamin Fischer $^{1} \cdot$ André Schuz $^{1} \cdot$ Johanne Dobringer $^{3}$ • \\ Luca Gentile $^{1}$ • Julio A. Vásquez ${ }^{3}$ • Julia C. Neubauer ${ }^{1}$ • Heiko Zimmermann ${ }^{1,2,3}$ (D)
}

Received: 24 October 2016 / Revised and accepted: 14 March 2017 / Published online: 4 April 2017

(C) The Author(s) 2017. This article is published with open access at Springerlink.com

\begin{abstract}
Nowadays, modern approaches in tissue engineering include the combination of therapeutic relevant cells with high quality, biocompatible biomaterials. The resulting cellularized scaffolds are of great interest for several pharmaceutical applications such as drug screening/discovery, disease modeling, and toxicity testing. In addition, the introduction of human-induced pluripotent stem cells (hiPSCs) further increased the importance and the potential of tissue engineering not only for the pharmaceutical industry, but also for future therapeutic applications. Artificial microenvironments of hiPSCs comprise combinations of adhesive proteins and are particularly influenced by mechanical properties of the growth surface. The increasing focus on mechanical properties and the ability to adjust them propose alginate hydrogels as suitable candidates for engineered scaffolds. Ultra-pure alginates, however, are bioinert and require modifications for bioactivation. In this study, we present two modifications of alginate hydrogels based on direct covalent coupling of collagen I and coupling of a special linker molecule with subsequent Matrigel coating. We were able to demonstrate the successful adhesion and proliferation of hiPSCs on these linkermodified alginates. The developed modifications are particularly applicable for planar as well as spherical hydrogel surfaces. In this context, a scalable adherent suspension
\end{abstract}

Heiko Zimmermann

heiko.zimmermann@ibmt.fraunhofer.de

1 Fraunhofer Institute for Biomedical Engineering, Joseph-von-Fraunhofer-Weg 1, 66280 Sulzbach, Germany

2 Molecular and Cellular Biotechnology/Nanotechnology, Saarland University, 66123 Saarbruecken, Germany

3 Facultad de Ciencias del Mar, Universidad Católica del Norte, Coquimbo, Chile culture on alginate microcarriers could be established. Our data further indicate that larger alginate microcarriers modified with collagen I is less susceptible for agglomeration compared to small microcarriers. The obtained results indicate these modifications as suitable for both adhesion and cultivation of human stem cells such as human mesenchymal stem cells or hiPSCs.

Keywords Alginate $\cdot$ Hydrogel $\cdot$ Tissue engineering $\cdot$ Stem cells $\cdot$ Scaffold

\section{Introduction}

The combination of promising therapeutically relevant cell lines with natural or synthetic biomaterials in the rapidly developing field of tissue engineering serves a common strategy for the generation of high valuable cell-based models (Fig. 1a) for both disease modeling (Prestwich 2007) and drug screening/discovery (Kimlin et al. 2013). In particular, knowledge gained from the cell-matrix interaction can be transferred to novel approaches in regenerative medicine such as cartilage repair (Re'em et al. 2010).

The used biomaterial represents more than a supporting "scaffold": it provides tissue- or cell-specific signals for proper functionality of the whole construct concerning, e.g., adhesion sites, cavities, chemical gradients, or elastic surfaces (Ghaemi et al. 2013; Gattazzo et al. 2014) and simultaneously influences the fate (see Fig. 1b) of human stem cells (Watt and Huck 2013). Due to this complexity, a rational design in a screening-like manner has not been conducted in the past, except for empirical "tissue try this" approaches (Kaplan et al. 2005; Ingber et al. 2006). Furthermore, surfaces coated by combinatorial proteins as well as the inclusion of compliant properties play key roles during the design of artificial cellular 


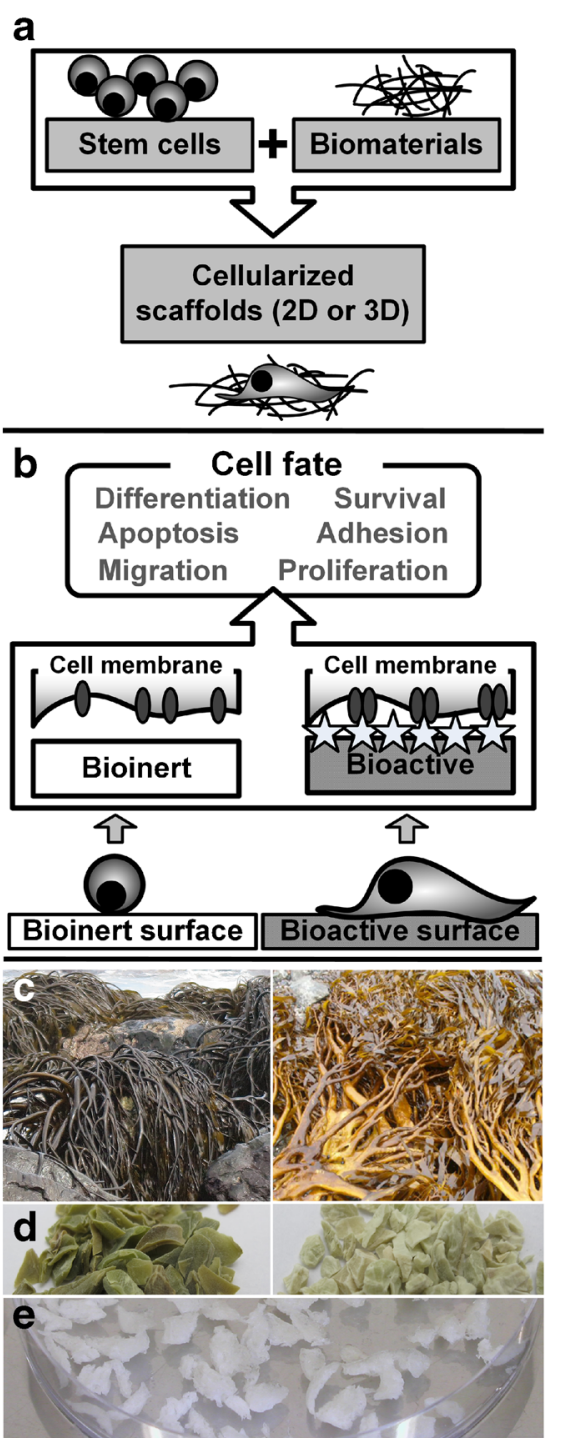

Fig. 1 Principles of tissue engineering: cells and materials. a Fundamental principle of tissue engineering. Therapeutic relevant cells are combined with biocompatible materials (natural or synthetic) to form cellularized artificial microenvironments. b Depending on the surface properties, signals from the outside (extracellular matrix) are "translated" by integrin-mediated interaction to the inner of the cell. Specific signals influence the general cell fate in terms of proliferation, survival, or adhesion. c Brown algae Lessonia nigrescens (left) and Lessonia trabeculata (right) used in biomaterial production for application in tissue engineering. d Raw product of Lessonia nigrescens (left) and Lessonia trabeculata (right) after initial cleaning and drying immediately after harvest. e Final purified alginate

environments (Discher et al. 2005; Buxboim et al. 2010). The direct influence of the elastic modulus of the surface has been demonstrated in several studies by both changes in morphology and the analysis of comprehensive gene expression studies (Engler et al. 2006). After decades of cell cultivation on stiff polystyrene surfaces, new scientific questions consequently arise concerning the interaction of cells with their mechanical surrounding, and thus, the complexity in designing artificial cellular environments increases. Since the introduction of human-induced pluripotent stem cells (hiPSCs), the demand for novel innovative, bioactive, and xeno-free surfaces for cultivation and differentiation workflows is continuously growing (Saha et al. 2011; de Peppo and Marolt 2013; Fan et al. 2014).

After the first description and generation of these cells (Takahashi and Yamanaka 2006; Takahashi et al. 2007), the scientific community is confronted with entirely new possibilities. Derived from somatic cells, such as fibroblasts from skin biopsies, hiPSCs can be reprogrammed by a defined set of genetic factors. Since these cells have a similar potential as human embryonic stem cells with less ethical concerns (Murphy et al. 2013), they can virtually be differentiated into each specialized cell of the human body (Lee et al. 2010; Lancaster and Knoblich 2014; Kempf et al. 2015). Furthermore, hiPSCs can be generated from patients with genetic disorders, and thus, the corresponding cells can be used for patient-specific drug testing (Gunaseeli et al. 2010; Ebert et al. 2012). In this context, compliant bioactive hydrogels can enhance both the current workflows during differentiation and the subsequent generated cell models.

One of the most promising candidates for engineering compliant in vivo-like surfaces are alginate hydrogels (Fig. 1c-e). Alginates can be isolated from brown algae and are unbranched polymers consisting of homogeneous or heterogeneous blocks of $\beta$-D-mannuronic or $\alpha$-L-guluronic acids (Draget et al. 2005). Protocols for the extraction of xeno-free, ultra-pure, high molecular weight alginates are available (Zimmermann et al. 2005; Fertah et al. 2014). The composition of the polymers, however, depends on the choice of algae species (Smidsrød and Skjåk-Bræk 1990), environmental conditions (Storz et al. 2009), or individual parts of the algae (stipe, leaf) (Dalheim et al. 2016). The gelation of alginate solutions occurs by ionotropic gelation under gentle conditions (Malpique et al. 2010) using divalent cations like $\mathrm{Ca}^{2+}$ or $\mathrm{Ba}^{2+}$ (Smidsrød and Skjåk-Bræk 1990). Since the alginate gelation can be conducted at physiological $\mathrm{pH}$ and temperatures, it is therefore particularly suited for applications in regenerative medicine and tissue engineering (Mettler et al. 2013). So far, alginates have been studied intensively in the context of immunoisolation of therapeutically relevant cells owing to development of novel approaches for treatment of diabetes mellitus (Duvivier-Kali et al. 2001; Schneider et al. 2005; Neufeld et al. 2013). Here, cells are encapsulated in a protective alginate shell, which can be implanted for therapeutic approaches. Due to the porosity of the alginate hydrogel, a bidirectional mass transfer of, e.g., oxygen, nutrients, metabolites, and active compounds from the inner of the alginate-capsule and vice versa, is still possible. For such an application, a bioinert material for the encapsulation is crucial to support long-term survival of the enclosed cells (Ponce et al. 2006). Crude alginates can lead to an immune response 
or to fibrosis, potentially inducing a loss of the transplant (van Schilfgaarde and de Vos 1999).

At the same time, such purified alginates are not suitable in terms of adherent cultivation of anchorage-dependent cells (Jeong et al. 2010) and only irregular surface characteristics (scratches) can lead to an cell adhesion of (rather simple) cell types such as fibroblasts (Zimmermann et al. 2007b). Machida-Sano et al. studied cell adhesion of alginates crosslinked with different cations and concluded that the protein adsorption on the hydrogel surface is one crucial factor for cell adhesion (Machida-Sano et al. 2009, 2014). Due to the hydrophilic properties of alginate hydrogels, low protein adsorption is expected. In this context, the usage of alginate surfaces for multipotent and especially for pluripotent stem cells is highly challenging. Pluripotent stem cells require a specialized cellular environment for adhesion guaranteeing survival (Chen et al. 2010; Kurosawa 2012) and maintaining/losing their identity (Sheridan et al. 2012). Bioactivation of alginate hydrogels by mixing proteins and polysaccharides is challenging due to complex chemical interactions of these macromolecules (Rodríguez Patino and Pilosof 2011). In addition, a transfer to spherical hydrogels is difficult regarding a proper presentation of the proteins at the surface (Terazono et al. 2012). Non-covalent mixing of these components for bioactivation represents a more suitable strategy for complete cell encapsulation in hydrogels (Sang et al. 2011). Furthermore, defined stem cell culture media do not provide any proteins that can adsorb on the alginate's surface and trigger cell adhesion (Fadeev and Melkoumian 2011). In order to cultivate human stem cells successfully on alginate hydrogels, it is essential to modify the polymers for engineering suitable stem cell environments.

Advanced specialized cultivation surfaces represent socalled microcarriers. Microcarriers are a valuable tool for cultivation of anchorage-dependent cells in static hanging droplet cultures or suspension cultures like stirred bioreactors. This cultivation method is increasingly important, since the production of the required high cell amounts is not possible using $2 \mathrm{D}$ cultivation systems. There is a high demand for novel innovative cell expansion substrates in large biorepositories such as the European Bank for induced pluripotent Stem Cells (EBiSC, www.ebisc.org). Thereby, the advantages of homogeneous cultivation conditions (e.g., no chemical gradients) can be applied to adherent cell lines with an excellent surface-to-volume ratio.

Microcarriers, introduced for the first time in 1967 (Van Wezel 1967), can be described as solid, porous, or macroporous with densities between 0.9 and $1.32 \mathrm{~g} \mathrm{~mL}^{-1}$ (Chen et al. 2013). The diameters of microcarriers vary from 120 to $300 \mu \mathrm{m}$ (Kong et al. 1999; Chen et al. 2013; Goh et al. 2013). In addition, microcarriers are functionalized with different surface features like charge or protein coatings. Common materials used for commercial microcarrier production are DEAE-dextran, cellulose, polystyrene, alginate, glass, or gelatin and allow the efficient cultivation with extremely high surface-to-volume ratio (Kong et al. 1999; Asthana and Kisaalita 2012; Chen et al. 2013; Goh et al. 2013). Despite the great success of these microcarriers, there is still a high demand for adoptable microcarrier systems in terms of mechanical properties, size, and biochemical functionalization. In our opinion, microcarriers based on ultra-high-viscosity (UHV)-alginate hydrogels can provide several of the posed demands due to their unique and partially adjustable properties. They can be adjusted concerning diameter, stiffness, porosity, surface properties, and the functionalization of the microcarrier's core by bioactive molecules such as growth factors. The functionalization of the surface accessible for the attachment of cells can be induced with proteins like collagen, fibronectin, or vitronectin.

In this study, we investigated the specific functionalization of cross-linked alginate surfaces in order to immobilize proteins with bioactive, cell-recognizable motifs triggering cell adhesion. We studied two different ways of bioactivation: one direct method by coupling proteins and one universal, indirect approach for adsorption of complex protein mixtures on the alginate's surface. The generated surfaces have been evaluated with two promising human stem cell types/lines: human mesenchymal stem cells (hMSCs) and hiPSCs. In consequence, our study provides a basis for future research on sophisticated cell models or transplants for regenerative medicine, disease modeling, or drug screening/discovery.

\section{Materials and methods}

\section{Seaweed-derived alginates}

In this study, we used alginates from the brown algae Lessonia nigrescens (LN) and Lessonia trabeculata (LT) procured in dry state from Alginatec GmbH, Riedenheim, Germany. The two species differ in chemical composition (mannuronic/ guluronic acid ratio) and thus in the final mechanical properties of the hydrogel after cross-linking. Raw materials were cleaned, peeled, chopped, and dried under controlled conditions immediately after harvest to minimize contamination. The extraction of alginates was conducted under sterile conditions. Purification of the alginate extract was by sterile filtration and a series of subsequent precipitations in ethanol and re-solution in potassium chloride solution. The final purified alginate was dried and stored at $+4{ }^{\circ} \mathrm{C}$ until usage. A detailed description of the production of purified ultra-high viscous alginates is given by Zimmermann et al. (2005). The purified alginate is suitable for long-term cultivation of human cells (Schneider et al. 2005). For hydrogel formation, alginate granulates were dissolved in isotonic sodium chloride solution (Sigma) and mixed until complete solvation. Both alginate 
types were prepared separately as $0.7 \%(w \% / v \%)$ solutions and mixed in equal parts before usage.

\section{Cell culture of hMSCs}

Human mesenchymal stem cells (hMSCs, PromoCell GmbH, Heidelberg, Germany) were cultured and expanded in DMEM/F-12 (Gibco) containing 10\% fetal bovine serum, $100 \mathrm{U} \mathrm{mL}^{-1}$ penicillin/streptomycin (Gibco), and $1 \mathrm{ng} \mathrm{mL}^{-1}$ basic fibroblast growth factor (bFGF, Gibco). Cells were passaged using trypsin/EDTA $(0.05 \%$, Gibco) once a week or at a confluency of $80 \%$.

\section{Cell culture of hiPSC}

hiPSCs AXAi (Axiogenesis AG, Germany) were delivered by the manufacturer in cell culture flasks with a growth area of $175 \mathrm{~cm}^{2}$ and cultured until usage. Cells were expanded in "AX-IP-N8" cell culture medium provided by the manufacturer and exchanged at regular intervals. For experiments, cells were washed with DMEM/F-12 (Gibco), detached using TrypLE (Gibco), and dispersed in cell culture medium. The resulting single cell suspension was supplemented with ROCK inhibitor (Cayman Chemical) in order to avoid apoptosis.

\section{Alginate membrane modified with collagen I}

Cell culture dishes (Corning, cell culture treated, diameter $35 \mathrm{~mm}$ ) were treated with poly-L-lysine (Sigma, 1:10 dilution $(v \% / v \%)$ in phosphate-buffered saline) for $30 \mathrm{~min}$ at $37^{\circ} \mathrm{C}$. In order to provide positive charges to mediate alginate adhesion on the polystyrene surface, the solution was aspirated and the surface air-dried. Subsequently, $1 \mathrm{~mL}$ of alginate solution $(0.7 \%, w \% / v \%)$ was poured into the Petri dish and crosslinked for $15 \mathrm{~min}$ with $1 \mathrm{~mL} \mathrm{BaCl} l_{2}$ solution $(20 \mathrm{mM})$ at room temperature. The cross-linking of alginate solution was conducted using a $20 \mathrm{mM} \mathrm{BaCl}$ solution with $115 \mathrm{mM} \mathrm{NaCl}$ and $5 \mathrm{mM}$ L-histidine (all chemicals from Sigma). Next, cross-linking solution was aspirated and alginate surfaces were washed three times to remove excessive barium. Afterwards, the alginate membranes were activated (see Fig. 2a) by aqueous carbodiimide chemistry (adopted from (Rowley et al. 1999)), containing $N$-(3-dimethylaminopropyl)- $N$ '-ethylcarbodiimide hydrochloride (EDC, $200 \mathrm{mM}$, Sigma) and $N$ hydroxysuccinimide (NHS, $50 \mathrm{mM}$, Sigma) in aqua bidest for $30 \mathrm{~min}$ at room temperature. Subsequently, the beads were washed twice with aqua bidest. After activation, the membranes were incubated in different dilutions of collagen I $(0,7.5,37.5$, and $75 \mu \mathrm{g} \mathrm{mL}^{-1}$, from rat tail, Gibco, diluted in $1 \mathrm{~mL} 0.1 \mathrm{M}$ HEPES, pH 5.2, 0.1 osmol) overnight at room temperature (see Fig. 2b). The membranes were washed twice in $0.9 \% \mathrm{NaCl}$. hMSCs $\left(6250\right.$ cells per $\left.\mathrm{cm}^{2}\right)$ were inoculated in $2 \mathrm{~mL}$ culture

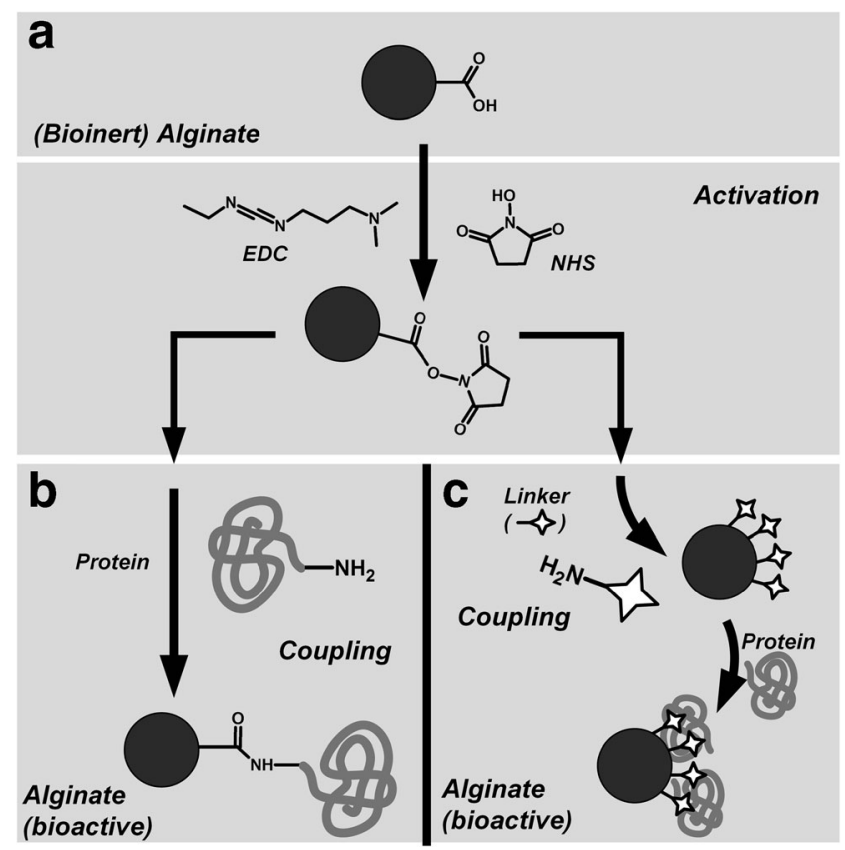

Fig. 2 Chemical treatment of alginate hydrogels for the production of bioactive surfaces. a Carboxyl groups of alginates are involved in the cross-linking of the hydrogel but can also be used for activation via aqueous carbodiimide chemistry (EDC and NHS). b Proteins or other bioactive compounds can directly be coupled on the alginate's surface. c Coupling of a linker molecule to alginate polymers for subsequent universal protein coating on alginate surfaces by adsorption. EDC 3dimethylaminopropyl)- $N^{\prime}$-ethylcarbodiimide hydrochloride, $N H S N$ hydroxysuccinimide

medium, observed, and cultivated for $8 \mathrm{~h}$ in automated microscopes (Biostation IM, Nikon). The number of attached cells (\% of total cells seeded) was quantified manually $1 \mathrm{~h}$ after inoculation.

\section{Alginate microcarriers modified with collagen I}

For the production of alginate microcarriers, alginate beads were produced by coaxial air jet technology (Zimmermann et al. 2005, 2007a). A 1:1 $(v \% / v \%)$ mixture of LN and LT alginate was prepared, and alginate spheres were generated by dropping the alginate into a barium chloride gelation bath (containing $20 \mathrm{mM} \mathrm{BaCl}_{2}, 115 \mathrm{mM} \mathrm{NaCl}$, and $5 \mathrm{mM} \mathrm{L}$-histidine). In addition, small alginate spheres (approx. $200 \mu \mathrm{m}$ diameter) and large alginate spheres (approx. $600-700 \mu \mathrm{m}$ ) were produced. To remove excessive gelating agents, the spheres were washed in $\mathrm{NaCl}(0.9 \%, w \% / v \%)$. In this form, alginate hydrogels are bioinert and no integrin-mediated adhesion of cells is triggered by physicochemical properties of the alginate spheres' surface. Hence, the alginate beads were activated by aqueous carbodiimide chemistry (adopted from (Rowley et al. 1999)) according to the former paragraph (see Fig. 2a, b). Subsequently, the beads were washed twice with aqua bidest. After activation, the beads were incubated in a $10 \mathrm{~mL}$ solution with $7.5 \mu \mathrm{g} \mathrm{mL}^{-1}$ collagen I (from rat tail, Gibco, diluted in 
0.1 M HEPES, pH 5.2, 0.1 osmol) overnight at room temperature. The produced alginate microcarriers were washed twice in $0.9 \% \mathrm{NaCl}$ and stored at $4{ }^{\circ} \mathrm{C}$ until usage and before cell seeding.

\section{Stirred microcarrier culture of hMSCs in mini-bioreactors}

For the cultivation of hMSCs, we used a suspension bioreactor system (BioLevitator, Hamilton Bonaduz AG, Switzerland) with four parallelized bioreactors (Levitubes, Hamilton Bonaduz AG, Switzerland). The parameters used for inoculation were 50-rpm rotation speed, 5-s rotation period, 2-s rotation pause, 2-min agitation period, and 10-min agitation pause for an overall duration of $4 \mathrm{~h}$. After inoculation, the cultivation was started with $60-\mathrm{rpm}$ rotation speed, 5-s rotation period, and 3 -s rotation pause for an overall duration of 7 days. We cultivated hMSCs on four different microcarrier systems: Cytodex 1 precoated with collagen I, Cytodex 3 (SigmaAldrich, Germany), and our two developed alginate microcarrier systems with different sizes as described earlier. The total growth area per condition was adjusted to $72 \mathrm{~cm}^{2}$. Suspensions of cells and microcarriers were inoculated at a density of 4000 cells per square centimeter in $40 \mathrm{~mL}$ culture medium. This proportion was the same for all types of microcarriers in the used suspension bioreactors. Half of the culture medium was exchanged once a week. For subsequent analysis, microscopic images were captured during the inoculation phase (1, 2, and $3 \mathrm{~h}$ ) as well as after 1, 3, 6, and 7 days. The distribution of the cells during the inoculation phase and the distribution of cell-microcarrier aggregates were determined manually. The confluent cell areas on microcarriers were determined manually after day 6 .

\section{Alginate membranes modified with a linker and coated with Matrigel}

Two alginate membranes in 60-mm Petri dishes (Nunc) were produced as described earlier. Alginate membranes were activated for $30 \mathrm{~min}$ at room temperature using $200 \mathrm{mM}$ EDC and $50 \mathrm{mM}$ NHS (see above, Fig. 2a). A solution of extracellular matrix proteins was prepared solving $1 \mathrm{mg}$ Matrigel (Corning) in $12 \mathrm{~mL}$ DMEM/F-12 (Beers et al. 2012) and poured onto the activated alginate surface. In addition, a sterile solution of $0.1 \mathrm{~g} \mathrm{~mL}^{-1}$ of the solution with the linker molecule was prepared with 0.1 mM HEPES (Sigma, 0.1 mM, pH 5.2) and poured onto the second activated alginate surface. Both preparations were incubated overnight at room temperature. Subsequently, samples were thoroughly rinsed with isotonic $\mathrm{NaCl}$ solution and DMEM/F-12. The alginate surface with directly coupled Matrigel (A-MG) was stored at $37{ }^{\circ} \mathrm{C}$ until usage (Fig. 2c). Again, a solution of $1 \mathrm{mg}$ in $12 \mathrm{~mL}$ DMEM/F-12 was prepared and poured onto a standard tissue culture polystyrene surface (Nunc) (T-MG) and on alginate surfaces modified with the linker (A-LKR-MG). Both preparations were incubated overnight at $37^{\circ} \mathrm{C}$. Before cell inoculation, the preparations were washed with DMEM/F-12 and sterilized for $15 \mathrm{~min}$ with UV light.

\section{hiPSC culture on bioactive alginate surfaces}

hiPSCs AXAi were inoculated (12,000 cells $\mathrm{cm}^{-2}$ ) and cultivated over 6 days. After $24 \mathrm{~h}$ the medium was exchanged and adherent cells were quantified (Millipore Scepter). After 6 days the cells were harvested and the cell number was determined.

\section{Statistics}

The data are presented as mean \pm standard deviation (SD) from three independent biological experiments. Data analysis was performed using OriginPro 2015b (OriginLab) for Microsoft Windows.

\section{Results}

\section{Production of bioactive alginate surfaces}

After long-time experience with the production of ultra-pure "clinical-grade" alginates (Jork et al. 2000; Zimmermann et al. 2005) and extensive studies on alginate hydrogels in the context of immunoisolation of pancreatic cells, we focused on the specific bioactivation of alginate hydrogels for applications in tissue engineering. Early approaches with ultra-high viscous alginate surfaces were conducted with highly concentrated collagen I solution and used a $\mathrm{pH}$ shift for non-covalent coating (Gröhn et al. 1997). These approaches could approve cell adhesion, but only in such cell systems with minimal requirements to their immediate microenvironment attached and spread (Gröhn et al. 1997). In this study, we investigated the specific modification of alginate hydrogels towards a bioactive surface for attachment and cultivation of human stem cells. We analyzed two principles of cell culture: adherent cultivation on planar hydrogels, as well as adherent suspension culture on spherical hydrogels that are in strong demand by industrial biotechnology, e.g., for large-scale production of therapeutics (Liu et al. 2007). The proposed protocol for alginate hydrogel modification is compatible with both systems and can be finalized within 1 or 2 days. During the modification steps, changed wettability of planar surfaces or increased "stickiness" of the spherical hydrogels on the reaction tubes was observed indicating changed chemical properties. The successful modification was evaluated by assessing cellular response in subsequent adhesion experiments with human stem cells. 


\section{Cultivation and expansion of hMSCs on planar bioactive alginate surfaces}

The initial experiments with collagen I bioactive alginate surfaces revealed, on the one hand, the functionality of the modification protocol for ultra-high viscous alginates and, on the other hand, the relatively fast cell reaction in terms of adhesion and spreading of cells. We coupled several amounts of collagen I onto the alginate's surface and measured the attached cell number (\% of cells seeded) after $1 \mathrm{~h}$ (Fig. 3a). The unmodified, native alginate surface allowed no cell adhesion; cells remained round and without membrane extrusions in suspension (Fig. 3b). After coupling of $7.5 \mu \mathrm{g}$ to the alginate's surface, first positive reactions could be observed (Fig. 3c). Cells start to attach and achieved an overall attachment rate of $56.7 \%( \pm 42.8 \%)$. The relatively high standard deviation results from one experiment with no cell adhesion. In summary, the reproducibility of this small protein concentration is critical in terms of stable modification workflows. At higher
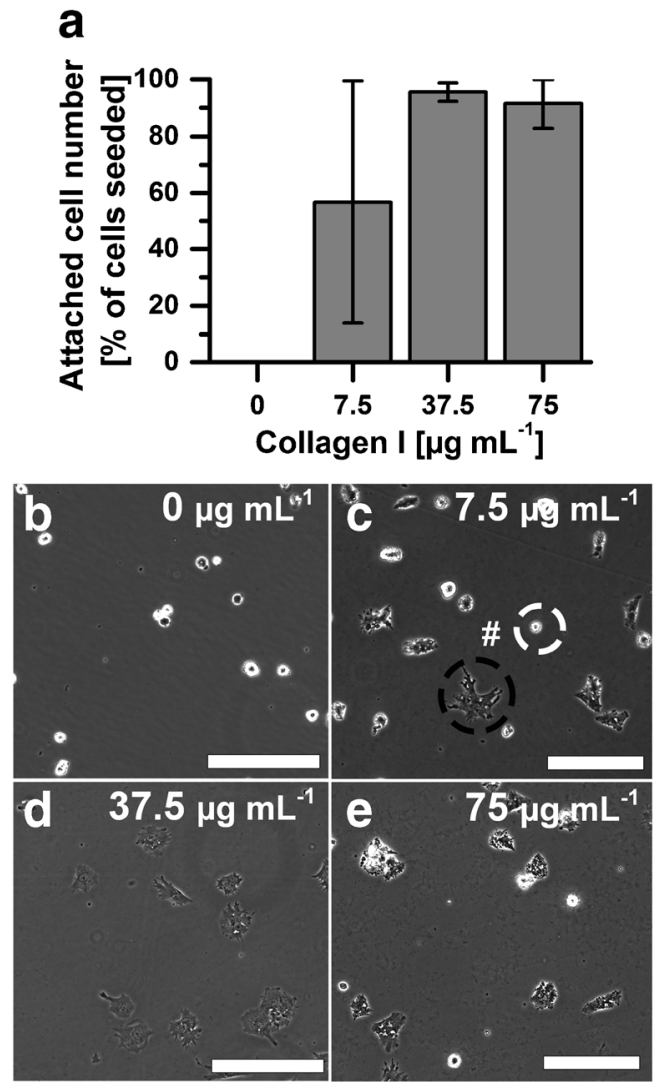

Fig. 3 a Attached hMSCs $1 \mathrm{~h}$ after inoculation on a bioactivated alginate surface with different collagen I moieties expressed as mean $\pm \operatorname{SD}(n=3$ independent experiments, cells in five fields of view were analyzed per experiment). b Mainly round cells are present on native alginate surfaces indicating no cell-matrix interactions. c Increased interactions were observed using alginates bioactivated with $7.5 \mu \mathrm{g} \mathrm{mL}^{-1}$ or higher. Number sign marks a bioactivated alginate surface, the white dashed circle encloses a non-attached cell, and the black dashed circle encloses an attached and spread cell. Most adherent cells were observed on d 37.5 and e $75 \mu \mathrm{g} \mathrm{mL}^{-1}$, respectively. Scale bar b-e $200 \mu \mathrm{m}$ concentrations, we observed both excellent cell adhesion behavior after $1 \mathrm{~h}$ and excellent reproducibility. At $37.5 \mu \mathrm{g}$ (Fig. 3d), 95.5\% ( $\pm 3.3 \%)$ cells attached and spread. At $75 \mu \mathrm{g}$ (Fig. 3e), 91.4\% $( \pm 8.5 \%)$ of the cells attached and spread. Overall, our data demonstrate the possibility of both stable bioactivation and a very fast cell attachment. Especially for non-static applications, such as an adherent suspension culture on microcarriers, a fast interaction is necessary for efficient cell inoculation of microcarriers. The fast cell adhesion on spherical alginate microcarrier is illustrated in Fig. $4 \mathrm{a}$.

\section{Cultivation and expansion of hMSCs on spherical bioactive alginate surfaces}

The cultivation of multipotent hMSCs on different microcarrier systems revealed the ability to use novel UHVbased alginate microcarriers for cultivation and expansion of cells in both static hanging droplet cultures and in suspension bioreactor systems. While Cytodex 1, Cytodex 3, and small UHV-alginate microcarriers showed a tendency to build large cell-microcarrier agglomerates (Fig. 4c), large UHV-alginate microcarriers remained mainly as single microcarrier systems (see Fig. 4b). The cell attachment on microcarriers was quantified during the inoculation phase, since the attachment of cells during this phase is crucial for further efficient cultivation and expansion (Frauenschuh et al. 2007). The mean cell number on Cytodex 1 was $3.3 \pm 1.5,3.6 \pm 1.4$, and $4.2 \pm 1.7$ after 1 , 2 and $3 \mathrm{~h}$, respectively. The mean cell number on Cytodex 3 was $2.7 \pm 1.4,3.6 \pm 1.9$, and $3.6 \pm 2.0$ after 1,2 and $3 \mathrm{~h}$. respectively. Small UHV-alginate microcarriers revealed a mean cell number of $4.0 \pm 2.6,6.0 \pm 4.0$, and $7.7 \pm 5.3$ after 1,2 , and $3 \mathrm{~h}$, respectively. Large UHV-alginate microcarriers demonstrated the highest cell numbers per microcarrier with $7.8 \pm 3.8,9.0 \pm 4.6$, and $10.5 \pm 4.5$ after 1,2 , and $3 \mathrm{~h}$, respectively (Fig. 4d).

The populated microcarriers cultivated in a rotating bioreactor were analyzed after 1 week concerning their tendency of agglomeration (Fig. 4e). According to the number of involved microcarriers, we divided the agglomerated microcarriers into five classes (1, 2, 3, 4, and more than four agglomerated microcarriers). The distribution was as follows (order 1, 2, 3, 4 , and more $\pm \mathrm{SD}$ ): $98.3 \pm 2.9,1.7 \pm 2.9,0.0 \pm 0.0,0.0 \pm 0.0$, and $0.0 \pm 0.0 \%$ for big alginate microcarriers. The distribution of small alginate microcarriers was $35.0 \pm 21.8,11.7 \pm 2.9$, $11.7 \pm 7.6,10.0 \pm 10.0$, and $31.7 \pm 12.6 \%$. In comparison, the distribution of Cytodex 1 microcarriers referred to $31.7 \pm 33.3$, $16.7 \pm 2.9,18.3 \pm 12.6,8.3 \pm 5.8$, and $25.0 \pm 17.3 \%$ and for Cytodex $320.0 \pm 15.0,16.7 \pm 12.6,20.0 \pm 8.7,8.3 \pm 2.9$, and $35.0 \pm 30.4 \%$. The distribution revealed a comparable behavior of agglomeration of small alginate, Cytodex 1, and Cytodex 3 microcarriers, if cultivated in a rotating bioreactor. In consequence, our data indicate that the large alginate microcarriers show a completely different 

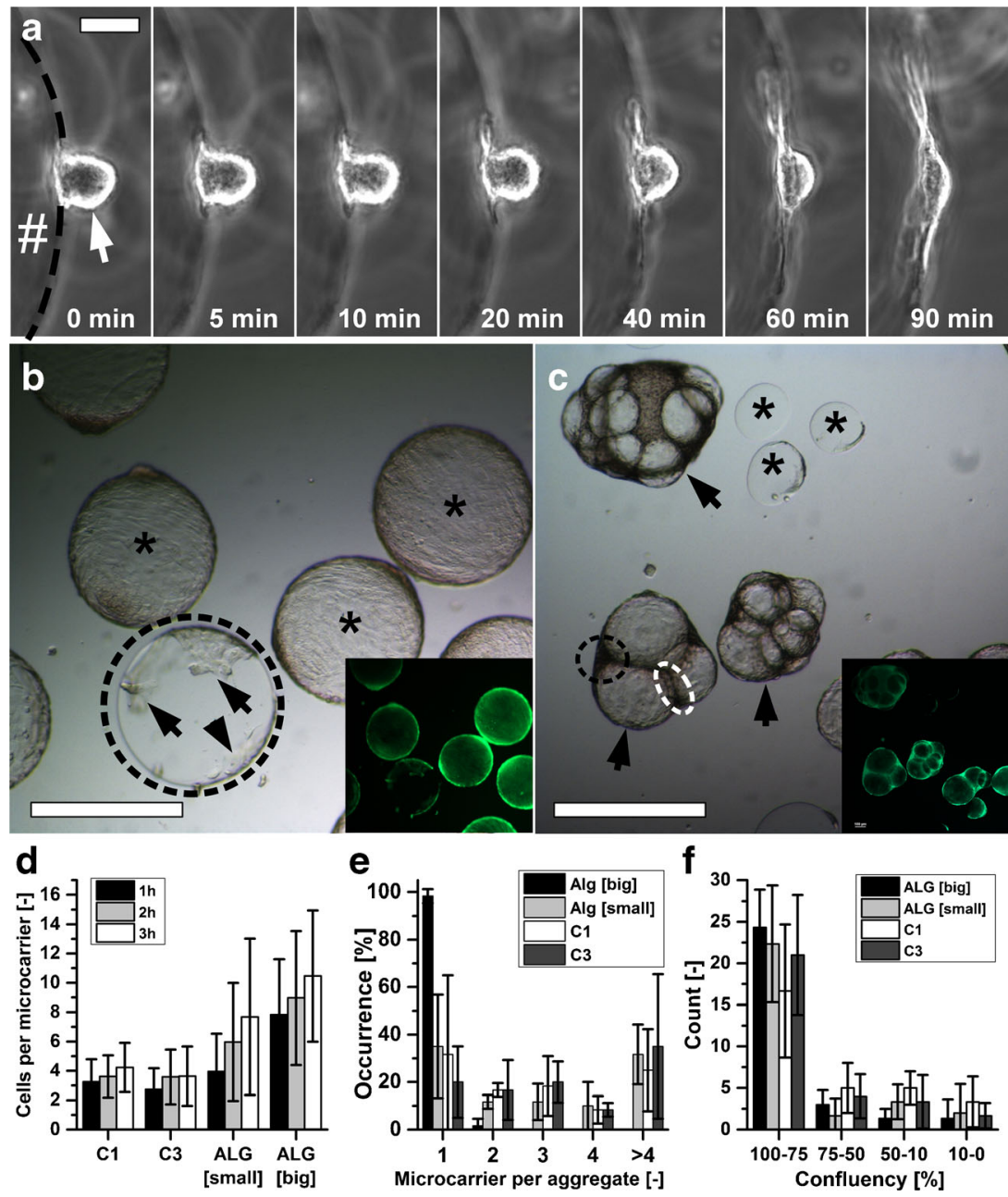

Fig. 4 a Time-lapse sequence of the attachment process of an hMSC cell (white arrow tip) on spherical alginates (number sign) modified with collagen I. b Large alginate microcarriers with collagen I, 7 days after cultivation in a rotating bioreactor. A complete coverage of the microcarriers with hMSC could be observed (black asterisks). The microcarrier encircled by a dashed line shows minor coverage by adherent hMSCs (black arrows). Inset: the corresponding image using a fluorescence microscope. hMSCs stained with fluorescein diacetate verify coverage of the microcarriers with hMSCs. $\mathbf{c}$ Small alginate microcarrier with collagen I after 7-day cultivation in a rotating bioreactor. hMSCs and microcarriers form complex agglomerates (black arrows). The black asterisks mark alginate microcarriers with minor cell coverage. The black dashed circle indicates an area of high cell density, and the white dashed circle indicates cell bridges of adjacent microcarriers. Inset:
Corresponding image using a fluorescence microscope. hMSCs stained with fluorescein diacetate verify coverage of the microcarriers with hMSCs. d Attachment of hMSCs on microcarriers after 1-, 2- and 3-h inoculation phase in a rotating bioreactor expressed as cells per microcarrier (mean $\pm \mathrm{SD}, n=3$ independent experiments, 30 microcarrier per experiment). e Quantified agglomeration of cellularized microcarriers after 7-day cultivation in a rotating bioreactor (mean $\pm \mathrm{SD}, n=3$ independent experiments, 20 analyzed aggregates per experiment). $f$ Confluency of hMSCs on microcarriers after 7-day cultivation (mean $\pm \mathrm{SD}, n=3$ independent experiments, $>25$ microcarriers analyzed per experiment). C1 Cytodex 1, C3 Cytodex 3, ALG [big] alginate microcarriers $500-\mu \mathrm{m}$ diameter, $A L G$ [small] alginate microcarriers 200- $\mu \mathrm{m}$ diameter. Scale bar in a indicates $20 \mu \mathrm{m}$; scale bar in b, c indicates $500 \mu \mathrm{m}$ behavior according to agglomeration with the used parameters. The vast majority of populated microcarriers did not agglomerate. After day 6, the expansion (proliferation) of hMSCs was investigated by measuring the confluency (proportion of surface covered with cells). The confluency was used as a parameter for cell proliferation (Curl et al. 2004) since we were also confronted with low yields using enzymatic detachment of cells as it is reported by other research groups (Weber et al. 2007; Rafiq et al. 2013; Nienow et al. 2016). The analysis of optimal cell detachment protocols from alginate microcarriers will consequently be part of subsequent studies. The most microcarriers, however, were overgrown in the range of 75 $100 \%$ (Fig. 4f) independent from the type of microcarrier. Overall, comparable confluency results were observed for all microcarrier types. 


\section{Cultivation and expansion of hiPSCs on planar bioactive alginate surfaces}

After inoculating a single cell suspension of hiPSCs on TCPScoated Matrigel (T-MG, Fig. 5a), alginate directly modified with Matrigel (A-MG, Fig. 5b), and alginate modified with the linker molecule and coated with Matrigel (A-LKR-MG, Fig. 5c), a fast cell response was observed on T-MG and ALKR-MG surfaces. Cells attached and spread within $1 \mathrm{~h}$. Since longer resting time in suspension might trigger apoptosis (Krawetz et al. 2009), this fact is essential. Furthermore, cells started to form colonies with close cell-cell contacts, the typical arrangement of these cells. On alginate, cells barely attach on the alginate's surface and remain still in suspension. After $24 \mathrm{~h}$, the lowest number of attached cells was measured on A-MG $(58.0 \pm 15.6 \%)$, whereas the number of attached cells was comparable between T-MG $(81.7 \pm 13.9 \%)$ and ALKR-MG (77.1 $\pm 15.0 \%$, Fig. 5d). A continuous proliferation of cells was observed during the experiments on T-MG as well as on A-LKR-MG surfaces. The end-point analysis (Fig. 5e) showed 38.3-fold ( \pm 5.8$)$ increase on T-MG surfaces and 11.2fold $( \pm 9.0)$ increase on T-LKR-MG surfaces. In contrast, cells on A-MG obtained a 0.9 -fold $( \pm 0.7)$ decrease.
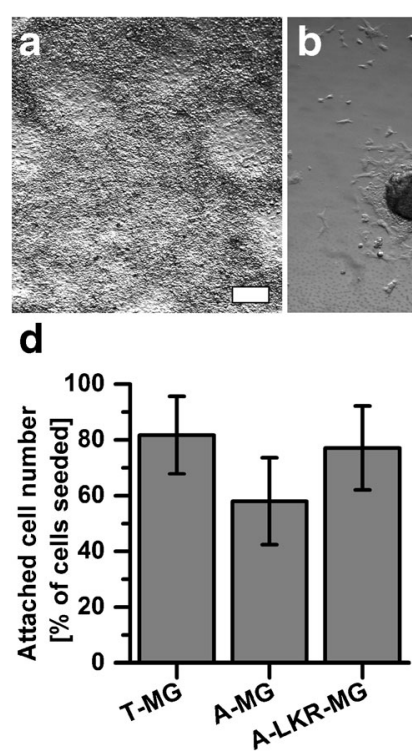
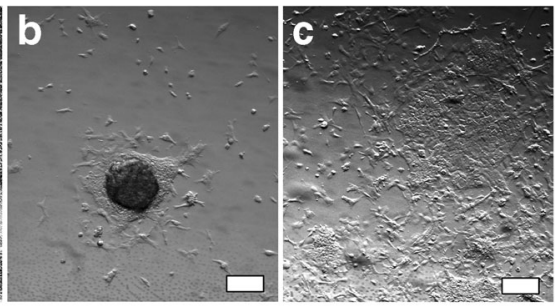

e

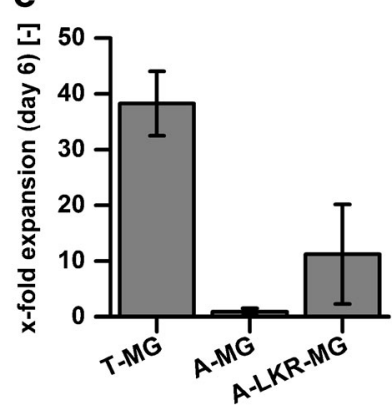

Fig. 5 Microscopic images of cell adhesion on a T-MG, b A-MG, and c A-LKR-MG. d Attached cells after $24 \mathrm{~h}$ on T-MG, A-MG, and A-LKRMG. Comparable numbers of adherent cells were observed on T-MG (standard cultivation surface) and A-LKR-MG. e Expansion of hMSCs after 6 days on different surfaces expressed $x$-fold expansion (mean $\pm \mathrm{SD}$, $n=3$ independent experiments). A 10-fold increase of hiPSCs was observed on alginate surfaces modified with the linker and coated with Matrigel. $T-M G$ TCPS coated with Matrigel, $A-M G$ Matrigel directly coupled on alginate, $A-L K R-M G$ alginate modified with the linker and coated with Matrigel. Scale bar in a-c $200 \mu \mathrm{m}$

\section{Discussion}

\section{Chemical modification of alginate hydrogels}

In this study, we established a stable protocol for covalent coupling of amide-containing molecules onto carboxyl groups of barium cross-linked alginates. Although introduced by Rowley et al. (1999) more than 15 years ago, an approach that utilizes a linker molecule for universal coating of alginates was still missing. Our ongoing experimental work also revealed that further therapeutically relevant cell types such as hiPSCs-derived cardiomyocytes are able to adhere and contract on these bioactive hydrogels (data not shown). First indications of mechanical interaction in terms of compression or deformation of hMSCs with the alginate have been observed during our experiments. In consequence, our future experiments will focus on cell-matrix interactions concerning, for example, cardiomyocytes.

\section{Adhesion of hMSCs and hiPSCs on bioactive alginates}

The conducted experiments with hMSCs demonstrated the ability to produce bioactive alginate surfaces for adult stem cells. Whereas hMSCs are per definition plastic-adherent (Dominici et al. 2006) or attach and spread on collagen I surfaces, a more sophisticated extracellular matrix (ECM) composition is necessary for the adhesion of hiPSCs. The protein mixture Matrigel consists of many different proteins, and hence, direct immobilization is challenging. We were able to verify our hypothesis that the introduction of proteininteraction groups in alginate hydrogels is an elegant and universal technique for protein coating as used in human stem cell biology (Beers et al. 2012). After coupling of a linker molecule, the alginate surface can be coated similar to standard petri dishes. To the best of our knowledge, the covalent coupling of a linker with subsequent Matrigel coating for cultivation of hiPSCs was never performed before our study. In addition, data from our most recent experiments (data not shown) revealed that hMSCs are in fact able to interact directly with alginates modified with the linker molecule most likely via increased adsorption of proteins, such as fibronectin present in serum-containing culture media (Grinnell and Feld 1982; Wilson et al. 2005).

In our experiments, hiPSCs revealed excellent attachment and adhesion on linker-modified alginates coated with Matrigel (see Fig. 5c, d). In contrast, direct coupling of Matrigel did not lead to reliable bioactive planar alginates (see Fig. 5b, d). The chemical composition of this protein mixture may serve as one explanation for this finding. Matrigel consists of more than 1000 different proteins (Hughes et al. 2010). Since the activation of the hydrogel's surface is conducted at low $\mathrm{pH}$, a precipitation/denaturation of proteins might be possible. The overall efficiency of the 
modification process might be affected. Despite the excellent adhesion of the cells, the proliferation on A-LKR-MG (see Fig. 5e) is reduced compared to the standard polystyrene petri dish coated with Matrigel (T-MG). The reduced different proliferation rates can arise due to different mechanical properties of the studied surfaces. While polystyrene is stiff, alginate provides a soft surface. Since cells are sensitive to the stiffness of their underlying substrate (Discher et al. 2005) until a depth of roughly $5 \mu \mathrm{m}$ (Buxboim et al. 2010), a direct influence on proliferation can be expected.

Furthermore, our data confirm our hypothesis that alginate hydrogels modified with the linker can be coated with Matrigel and, in consequence, mediate cell-matrix interactions. In our opinion, the prevalent molecular mechanisms refer to the increased adsorption of proteins from the Matrigel solution. We conclude that the modification of alginate hydrogels with a linker leads to chemical properties of the surface, which are similar to standard tissue culture-treated polystyrene (concerning wettability and protein adsorption), and thus can easily integrated in standard monolayer cell culture.

\section{Adherent suspension culture of hMSCs on microcarriers}

The variations in the cell attachment of small UHV-alginate microcarriers can be explained by variations in the microcarrier diameter caused by the production procedure. The formation of small alginate microcarriers was achieved by adjusting an alginate spray with large and small droplets. Though this heterogeneous distribution is not optimal for technical processes, it can serve as an interesting tool for the cultivation of cells on microcarriers, since this randomness is an increased degree of freedom in a macroscopic scale similar to the random organization of ECM fibers in cellular environments (van Loon et al. 2013).

The differences concerning the agglomeration behavior between the large and small alginate microcarriers as well as Cytodex 1 and 3 microcarriers can be explained by the cultivation setup in the used suspension bioreactor. The complex process of microcarrier-cell aggregation depends on the agitation rate or the inoculated cell density; however, this process is not yet completely understood (Ferrari et al. 2012). For cellbased models, agglomerated cell-microcarrier systems can be disadvantageous for long-term cultivation of anchoragedependent cell lines. In large agglomerated systems, the supply of cells with nutrients and oxygen can be limited, and in consequence, a decrease of viability can be expected. In bioreactors, the area of adjacent microcarriers, interacting over cell-cell contacts, is critical, since the exposition to high shear stress during cultivation causes cell death. Furthermore, the increasing agglomeration of microcarriers causes an adoption of agitation speed to avoid sedimentation of agglomerates (Cherry and Papoutsakis 1988).
The large alginate microcarriers reveal the potential ability to serve as an excellent system for cultivation of hMSCs in rotating bioreactors, since their dimension allows adhesion and spreading of larger cells like hMSCs. Obviously, on large alginate microcarriers, a larger amount of cells is able to grow, which can be crucial if a certain number of cell-cell contacts are required for efficient expansion or functionality. In contrast to rigid commercial available microcarrier systems, UHV-alginate microcarriers can be compressed by cellular tension and thus are more cell-responsible and comparable to in vivo environments. In conclusion, our experiments proved that covalent binding of individual proteins to alginate and subsequent cultivation of multipotent stem cells are possible.

This method is not only applicable for the different 2D and 3D cultivation methods of multipotent stem cells, but potentially likewise transferable to the newly developed xeno-free cultivation of pluripotent stem cells on vitronectin or laminin. The development of novel biomimetic cellular environments for differentiation and/or disease modeling indicates the greatest potential using both our alginate technology and the presented bioactivation procedure.

Acknowledgements This work was supported by a grant from the German Federal Ministry of Education (BMBF), given to H. Z. (grant no. 031581B). We would like to thank Dr. Sabine C. Mueller for careful proofreading.

\section{Compliance with ethical standards}

Conflict of interest The authors declare that they have no conflict of interest.

Open Access This article is distributed under the terms of the Creative Commons Attribution 4.0 International License (http:// creativecommons.org/licenses/by/4.0/), which permits unrestricted use, distribution, and reproduction in any medium, provided you give appropriate credit to the original author(s) and the source, provide a link to the Creative Commons license, and indicate if changes were made.

\section{References}

Asthana A, Kisaalita WS (2012) Biophysical microenvironment and 3D culture physiological relevance. Drug Discov Today 18:533-540

Beers J, Gulbranson DR, George N et al (2012) Passaging and colony expansion of human pluripotent stem cells by enzyme-free dissociation in chemically defined culture conditions. Nat Protoc 7:2029 2040

Buxboim A, Rajagopal K, Brown AEX, Discher DE (2010) How deeply cells feel: methods for thin gels. J Phys Condens Matter 22:194116

Chen A, Reuveny S, Oh S (2013) Application of human mesenchymal and pluripotent stem cell microcarrier cultures in cellular therapy: achievements and future direction. Biotech Adv 31:1032-1046

Chen G, Hou Z, Gulbranson DR, Thomson JA (2010) Actin-myosin contractility is responsible for the reduced viability of dissociated human embryonic stem cells. Cell Stem Cell 7:240-248 
Cherry RS, Papoutsakis ET (1988) Physical mechanisms of cell damage in microcarrier cell culture bioreactors. Biotechnol Bioeng 32:10011014

Curl CL, Bellair CJ, Harris PJ, Allman BE, Roberts A, Nugent KA, Delbridge LM (2004) Quantitative phase microscopy: a new tool for investigating the structure and function of unstained live cells. Clin Exp Pharmacol Physiol 31:896-901

Dalheim M, Vanacker J, Najmi MA, Aachmann FL, Strand BL, Christensen BE (2016) Efficient functionalization of alginate biomaterials. Biomaterials 80:146-156

de Peppo GM, Marolt D (2013) Modulating the biochemical and biophysical culture environment to enhance osteogenic differentiation and maturation of human pluripotent stem cell-derived mesenchymal progenitors. Stem Cell Res Ther 4:106. doi:10.1186/scrt317

Discher DE, Janmey P, Wang Y-L (2005) Tissue cells feel and respond to the stiffness of their substrate. Science 310:1139-1143

Dominici M, Le Blanc K, Mueller I, Slaper-Cortenbach I, Marini F, Krause D, Deans R, Keating A, Dj P, Horwitz E (2006) Minimal criteria for defining multipotent mesenchymal stromal cells. The International Society for Cellular Therapy position statement. Cytotherapy 8:315-317

Draget KI, Smidsrød O, Skjåk-Bræk G (2005) Alginates from algae. In: Steinbüchel A, Rhee SK (eds) Polysaccharides and polyamides in the food industry. Wiley-VCH, Weinheim, pp 1-30

Duvivier-Kali VF, Omer A, Parent RJ, O’Neil JJ, Weir GC (2001) Complete protection of islets against allorejection and autoimmunity by a simple barium-alginate membrane. Diabetes 50:1698-1705

Ebert AD, Liang P, Wu JC (2012) Induced pluripotent stem cells as a disease modeling and drug screening platform. J Cardiovasc Pharmacol 60:408-416

Engler AJ, Sen S, Sweeney HL, Discher DE (2006) Matrix elasticity directs stem cell lineage specification. Cell 126:677-689

Fadeev AG, Melkoumian Z (2011) Synthetic surfaces for human embryonic stem cell culture. In: Kallos M (ed) Embryonic stem cellsbasic biology to bioengineering. InTech, pp 89-104

Fan Y, Wu J, Ashok P, Hsiung M, Tzanakakis ES (2014) Production of human pluripotent stem cell therapeutics under defined xeno-free conditions: progress and challenges. Stem Cell Rev Rep 11:96-109

Ferrari C, Balandras F, Guedon E, Olmos E, Chevalot I, Marc A (2012) Limiting cell aggregation during mesenchymal stem cell expansion on microcarriers. Biotechnol Prog 28:780-787

Fertah M, Belfkira A, Dahmane EM, Taourirte M, Brouillette F (2014) Extraction and characterization of sodium alginate from Moroccan Laminaria digitata brown seaweed. Arab J Chem. doi:10.1016/j. arabjc.2014.05.003

Frauenschuh S, Reichmann E, Ibold Y, Goetz PM, Sittinger M, Ringe J (2007) A microcarrier-based cultivation system for expansion of primary mesenchymal stem cells. Biotechnol Prog 23:187-193

Gattazzo F, Urciuolo A, Bonaldo P (2014) Extracellular matrix: a dynamic microenvironment for stem cell niche. Biochim Biophys Acta Gen Subj 1840:2506-2519

Ghaemi SR, Harding FJ, Delalat B, Gronthos S, Voelcker NH (2013) Exploring the mesenchymal stem cell niche using high throughput screening. Biomaterials 34:7601-7615

Goh TK-P, Zhang Z-Y, Chen AK-L, Reuveny S, Choolani M, Chan JK, Oh SK (2013) Microcarrier culture for efficient expansion and osteogenic differentiation of human fetal mesenchymal stem cells. Biores Open Access 2:84-97

Grinnell F, Feld MK (1982) Fibronectin adsorption on hydrophilic and hydrophobic surfaces detected by antibody-binding and analyzed during cell-adhesion in serum-containing medium. J Biol Chem 257:4888-4893

Gröhn P, Klöck G, Zimmermann U (1997) Collagen-coated Ba ${ }^{2+}$-alginate microcarriers for the culture of anchorage-dependent mammalian cells. BioTechniques 22:970-975
Gunaseeli I, Doss M, Antzelevitch C, Hescheler J, Sachinidis A (2010) Induced pluripotent stem cells as a model for accelerated patientand disease-specific drug discovery. Curr Med Chem 17:759-766

Hughes CS, Postovit LM, Lajoie GA (2010) Matrigel: a complex protein mixture required for optimal growth of cell culture. Proteomics 10: 1886-1890

Ingber DE, Mow VC, Butler D, Niklason L, Huard J, Mao J, Yannas I, Kaplan D, Vunjak-Novakovic G (2006) Tissue engineering and developmental biology: going biomimetic. Tissue Eng 12:3265-3283

Jeong SI, Krebs MD, Bonino CA, Khan SA, Alsberg E (2010) Electrospun alginate nanofibers with controlled cell adhesion for tissue engineering. Macromol Biosci 10:934-943

Jork A, Thürmer F, Cramer H, Zimmermann G, Gessner P, Hämel K, Hofmann G, Kuttler B, Hahn HJ, Josimovic-Alasevic O, Fritsch KG, Zimmermann U (2000) Biocompatible alginate from freshly collected Laminaria pallida for implantation. Appl Microbiol Biotechnol 53:224-229

Kaplan DL, Moon RT, Vunjak-Novakovic G (2005) It takes a village to grow a tissue. Nat Biotechnol 23:1237-1239

Kempf H, Kropp C, Olmer R, Martin U, Zweigert R (2015) Cardiac differentiation of human pluripotent stem cells in scalable suspension culture. Nat Protoc 10:1345-1361

Kimlin L, Kassis J, Virador V (2013) 3D in vitro tissue models and their potential for drug screening. Expert Opin Drug Discov 8:1455-1466

Kong D, Chen M, Gentz R, Zhang J (1999) Cell growth and protein formation on various microcarriers. Cytotechnology 29:151-158

Krawetz RJ, Li X, Rancourt DE (2009) Human embryonic stem cells: caught between a ROCK inhibitor and a hard place. BioEssays 31: 336-343

Kurosawa H (2012) Application of Rho-associated protein kinase (ROCK) inhibitor to human pluripotent stem cells. J Biosci Bioeng 114:577-581

Lancaster MA, Knoblich JA (2014) Generation of cerebral organoids from human pluripotent stem cells. Nat Protoc 9:2329-2340

Lee G, Chambers SM, Tomishima MJ, Studer L (2010) Derivation of neural crest cells from human pluripotent stem cells. Nat Protoc 5: 688-701

Liu CC, Lian WC, Butler M, Wu SC (2007) High immunogenic enterovirus 71 strain and its production using serum-free microcarrier Vero cell culture. Vaccine 25:19-24

Machida-Sano I, Hirakawa M, Matsumoto H, Kamada M, Ogawa S, Satoh N, Namiki H (2014) Surface characteristics determining the cell compatibility of ionically cross-linked alginate gels. Biomed Mater 9:25007

Machida-Sano I, Matsuda Y, Namiki H (2009) In vitro adhesion of human dermal fibroblasts on iron cross-linked alginate films. Biomed Mater 4:25008

Malpique R, Osório LM, Ferreira DS, Ehrhart F, Brito C, Zimmermann $\mathrm{H}$, Alves PM (2010) Alginate encapsulation as a novel strategy for the cryopreservation of neurospheres. Tissue Eng Part C Methods 16:965-977

Mettler E, Trenkler A, Feilen PJ, Wiegand F, Fottner C, Ehrhart F, Zimmermann H, Hwang YH, Lee DY, Fischer S, Schreiber LM, Weber MM (2013) Magnetic separation of encapsulated islet cells labeled with superparamagnetic iron oxide nano particles. Xenotransplantation 20:219-226

Murphy CM, O'Brien FJ, Little DG, Schindeler A (2013) Cell-scaffold interactions in the bone tissue engineering triad. Eur Cell Mater 26: $120-132$

Neufeld T, Ludwig B, Barkai U et al (2013) The efficacy of an immunoisolating membrane system for islet xenotransplantation in minipigs. PLoS One 8:e70150

Nienow AW, Hewitt CJ, Heathman TRJ, Glyn VAM, Fonte GN, Hanga MP, Coopman K, Rafiq QA (2016) Agitation conditions for the culture and detachment of hMSCs from microcarriers in multiple bioreactor platforms. Biochem Eng J 108:24-29 
Ponce S, Orive G, Hernández R, Gascón AR, Pedraz JL, de Haan BJ, Faas MM, Mathieu HJ, de Vos P (2006) Chemistry and the biological response against immunoisolating alginate-polycation capsules of different composition. Biomaterials 27:4831-4839

Prestwich GD (2007) Simplifying the extracellular matrix for 3-D cell culture and tissue engineering: a pragmatic approach. J Cell Biochem 101:1370-1383

Rafiq QA, Brosnan KM, Coopman K, Nienow AW, Hewitt CJ (2013) Culture of human mesenchymal stem cells on microcarriers in a 51 stirred-tank bioreactor. Biotechnol Lett 35:1233-1245

Re'em T, Tsur-Gang O, Cohen S (2010) The effect of immobilized RGD peptide in macroporous alginate scaffolds on TGF $\beta 1$-induced chondrogenesis of human mesenchymal stem cells. Biomaterials 31 : 6746-6755

Rodríguez Patino JM, Pilosof AMR (2011) Protein-polysaccharide interactions at fluid interfaces. Food Hydrocoll 25:1925-1937

Rowley JA, Madlambayan G, Mooney DJ (1999) Alginate hydrogels as synthetic extracellular matrix materials. Biomaterials 20:45-53

Saha K, Mei Y, Reisterer CM, Pyzocha NK, Yang J, Muffat J, Davies MC, Alexander MR, Langer R, Anderson DG, Jaenisch R (2011) Surface-engineered substrates for improved human pluripotent stem cell culture under fully defined conditions. Proc Natl Acad Sci U S A 108:18714-18719

Sang L, Luo D, Xu S, Wang X, Li X (2011) Fabrication and evaluation of biomimetic scaffolds by using collagen - alginate fibrillar gels for potential tissue engineering applications. Mater Sci Eng C 31:262-271

Schneider S, Feilen PJ, Brunnenmeier F, Minnemann T, Zimmermann H, Zimmermann U, Weber MM (2005) Long-term graft function of adult rat and human islets encapsulated in novel alginate-based microcapsules after transplantation in immunocompetent diabetic mice. Diabetes 54:687-693

Sheridan SD, Surampudi V, Rao RR (2012) Analysis of embryoid bodies derived from human induced pluripotent stem cells as a means to assess pluripotency. Stem Cells Int 2012:738910

Smidsrød O, Skjåk-Bræk G (1990) Alginate as immobilization matrix for cells. Trends Biotechnol 8:71-78

Storz H, Müller KJ, Ehrhart F, Gómez I, Shirley SG, Gessner P, Zimmermann G, Weyand E, Sukhorukov VL, Forst T, Weber MM, Zimmermann H, Kulicke W-M, Zimmermann U (2009)
Physicochemical features of ultra-high viscosity alginates. Carbohydr Res 344:985-995

Takahashi K, Tanabe K, Ohnuki M, Narita M, Ichisaka T, Tomoda K, Yamanaka S (2007) Induction of pluripotent stem cells from adult human fibroblasts by defined factors. Cell 131:861-872

Takahashi K, Yamanaka S (2006) Induction of pluripotent stem cells from mouse embryonic and adult fibroblast cultures by defined factors. Cell 126:663-676

Terazono H, Kim H, Hayashi M, Hattori A, Nomura F, Kaneko T, Yasuda $\mathrm{K}$ (2012) A non-destructive culturing and cell sorting method for cardiomyocytes and neurons using a double alginate layer. PLoS One 7:e42485

van Loon SLM, Smits A, Driessen-Mol A, Baaijens FPT, Bouten CVC (2013) The immune response in in situ tissue engineering of aortic heart valves. In: Aikawa E (ed) Calcific aortic valve disease. Riejeka, InTech, pp 207-245

van Schilfgaarde R, de Vos P (1999) Factors influencing the properties and performance of microcapsules for immunoprotection of pancreatic islets. J Mol Med 77:199-205

Van Wezel AL (1967) Growth of cell-strains and primary cells on microcarriers in homogeneous culture. Nature 216:64-65

Watt FM, Huck WTS (2013) Role of the extracellular matrix in regulating stem cell fate. Nat Rev Mol Cell Biol 14:467-473

Weber C, Pohl S, Pörtner R, Wallrapp C, Kassem M, Geigle P, Czermak P (2007) Expansion and harvesting of hMSC-TERT. Open Biomed Eng J 1:38-46

Wilson CJ, Clegg RE, Leavesley DI, Pearcy MJ (2005) Mediation of biomaterial-cell interactions by adsorbed proteins: a review. Tissue Eng 11:1-18

Zimmermann H, Shirley SG, Zimmermann U (2007a) Alginate-based encapsulation of cells: past, present, and future. Curr Diab Rep 7: 314-320

Zimmermann H, Wählisch F, Baier C et al (2007b) Physical and biological properties of barium cross-linked alginate membranes. Biomaterials 28:1327-1345

Zimmermann H, Zimmermann D, Reuss R et al (2005) Towards a medically approved technology for alginate-based microcapsules allowing long-term immunoisolated transplantation. J Mater Sci Mater Med 16:491-501 